\title{
PERBANDINGAN METODE KONVENSIONAL DENGAN BIM TERHADAP EFISIENSI BIAYA, MUTU, WAKTU
}

\author{
Rizal Maulana Rizqy ${ }^{1}$, Nunung Martina ${ }^{2}$, Hari Purwanto ${ }^{3}$ \\ ${ }^{1.2}$ Jurusan Teknik Sipil, Politeknik Negeri Jakarta, Jalan Prof.Dr.G.A. Siwabessy, Kampus Baru UI, \\ Kukusan, Kecamatan Beji, Kota Depok, Jawa Barat, 16424 \\ e-mail : rizmaulana26@gmail.com,nunung.martina@sipil.pnj.ac.id, hari.purwanto@sipil.pnj.ac.id
}

\begin{abstract}
The construction field in Indonesia has been developing briskly. It can be proved by the discovery of the new method in the construction field, the Building Information Modelling (BIM) method. This BIM method is claimed to help finish the work more effective and less cost compare using the previous methods. It is because each application should be made manually and separately. Unlike the conventional method, the BIM method has the applications integrated into one, so it can accelerate the work progress and minimalize human resources. This research discusses the contrast of the construction planning process, especially when making the work method, and shop drawing, which reviewed from cost, quality, and time aspect. This research also examines the advantages and disadvantages of using the BIM method because it is categorized as a new method. The questionnaire and the interview method are used to collect the data. This research subject is the drafters and engineers already experienced in the construction field by applying the BIM method. The case of this study is Toll Road Jakarta Cikampek II Selatan (Paket 3), with comparing the cost and time efficiency between conventional and BIM methods. The results show that the work will be done $43.82 \%$ faster using the BIM method than the conventional one. However, the required cost will be more expensive by using the BIM method because it will be allocated to invest in the software license.
\end{abstract}

Keywords: Cost, quality, and time; Building Information Modelling (BIM); Conventional methods

\begin{abstract}
ABSTRAK
Perkembangan dunia konstruksi yang sudah sangat pesat di Indonesia terbukti dengan adanya metode baru untuk konstruksi yaitu Building Information Modelling (BIM). BIM ini diklaim dapat membuat pekerjaan menjadi efektif, efisien dan dapat menghemat biaya dibandingkan metode konvensional. Tidak seperti metode konvensional, BIM dapat terintegerasi antar aplikasinya satu sama lain, sehingga dapat mempercepat proses pekerjaan yang akan menyingkat waktu dan juga membuat sumber daya manusia menjadi lebih sedikit. Dalam penelitian ini akan dijelaskan apa saja perbedaan jelas proses perencaan konstruksi khususnya saat pembuatan metode kerja dan shopdrawing yang ditinjau dari segi biaya, mutu, waktu. Dan juga akan mengetahui apa saja kelebihan dan kekurangan BIM karena ini adalah sesuatu yang baru, maka dari itu untuk penelitian ini dilakukan dengan metode kueisioner dan wawancara kepada para draftrer dan engineer yang sudah berkecimpung didunia konstruksi dan sudah menggunakan BIM. Dengan studi kasus perencanaan Jalan Tol Jakarta-Cikampek II Selatan (Paket 3) dilakukan perbandingan efiseiensi biaya dan waktu dengan metode konvensional dan BIM. Penelitian ini menghasilkan kesimpulan bahwa aplikasi BIM dapat mempercepat proses pelaksanaan kerja sebesar $43.82 \%$, tetapi berbeda dengan biaya lebih mahal dari konvensional dikarenakan biaya investasi awal untuk lisensi software yang mahal.
\end{abstract}

Kata kunci: Biaya, mutu dan waktu; Bulding Information Modelling (BIM); metode konvensional 


\section{PENDAHULUAN}

Pada era globalisasi, kemajuan teknologi informasi saat ini sudah sangat pesat, tidak terkecuali dengan perkembangan teknologi pada proyek konstruksi yang akan berdampak pula pada keefektifan dan keefisienan hasil kerja. Karena akan sangat berbeda apabila masih menggunakan metode konvensional dengan metode BIM. BIM atau yang biasa disebut Intregrated Project Delivery (IPD) adalah suatu permodelan untuk desain, pelaksanaan dan penyampaian desain bangunan dengan kolaborasi, penyatuan dan pengorganisasian tim yang produktif dari suatu sistem pengendalian pelaksanaan proyek. Tujuan dari diciptakannya suatu sistem Intregrated Project Delivery adalah untuk mengurangi kesalahan, kerusakan dan biaya saat keseluruhan pelaksanaan desain, konstruksi dan proses pelaksanaan [1].

BIM saat ini sudah berkembang di negara-negara maju. Sebagian besar perusahaan konstruksi di Indonesia masih menggunakan perangkat lunak konvensional seperti AutoCad untuk desain gambar, SAP untuk analisa struktur, Ms. Excel untuk perhitungan volume dan biaya, dan Ms. Project untuk penjadwalan. BIM mengubah seluruh konsep perencanaan dengan memperkenalkan suatu proses untuk mengembangkan desain dan dokumentasi konstruksi. Dokumen konstruksi seperti gambar, rincian pengadaan, dan spesifikasi lainnya dapat dengan mudah saling terkait [2]. Metode perencanaan konvensional merupakan metode yang digunakan dengan cara lama atau metode yang telah dilakukan sejak dulu. Biasanya ada beberapa alternatif metode perencanaan yang dipakai salah satunya adalah metode konvensional yang selama ini dipakai di Indonesia, tetapi metode ini memiliki beberapa kekurangan seperti membutuhkan waktu yang lama, kontrol kualitas yang kurang baik, dan biaya yang banyak sehingga dirasa kurang efisien dari segi biaya, mutu, dan waktu [3]. BIM merubah seluruh konsep perencanaan dengan memperkenalkan suatu proses yang digunakan untuk mengembangkan desain dan dokumentasi konstruksi seperti gambar, rincian pengadaan dan spesifikasi lainnya dapat dengan mudah saling terkait $[2,4]$.

Konsep BIM membayangkan konstruksi virtual sebelum konstruksi fisik yang sebenarnya, untuk mengurangi ketidakpastian, meningkatkan keselamatan, menyelesaikan masalah, dan menganalisis dampak potensial [5]. Dalam penggunaan BIM ada faktorfaktor yang mempengaruhi dalam penggunaannya, yaitu software atau teknologi yang digunakan harus sudah memenuhi persyaratan, lalu ada keahlian penggunanya yang dimana pengguna ini harus memiliki extra skill agar tidak terjadi kesalahan, dan yang terakhir adalah proses pemakaian building information modeling sendiri [6]. Permasalahan yang sering muncul dalam dunia konstruksi adalah masalah produktivitas tenaga kerja. Untuk penanganan masalah yang berkaitan dengan produktivitas hendaknya mengarah pada kemampuan dan kualitas sumber daya manusia terutama para pengelolanya [7]. Dalam suatu proyek konstruksi biaya proyek merupakan salah satu aspek penting dan sangat perlu dikendalikan agar sesuai dengan budget yang telah dianggarkan sehingga dapat menghasilkan keuntungan proyek yang maksimal.[8]. Dalam perencanaan proyek, mutu adalah hal yang juga pentingnya. Pengendalian mutu adalah bagian utama agar proyek dapat diselesaikan dengan mutu yang dapat dipertanggung jawabkan memenuhi persyaratan pelanggan. tercapai atau 
tidaknya tujuan suatu proyek ditentukan oleh peran pengendalian dan pengawasan [9]. Pengendalian waktu merupakan salah satu elemen hasil perencanaan, yang dapat memberikan informasi tentang jadwal rencana dan kemajuan poyek dalam hal kinerja sumber daya berupa biaya, tenaga kerja, peralatan dan material serta rencana durasi proyek dan progress waktu untuk menyelesaikan proyek [10].

Permasalahan dari penelitian ini adalah apa saja perbedaan yang terlihat pada proses pelaksanaan pekerjaan shopdrawing perencanaan proyek konstruksi yang diukur dalam parameter efiseiensi biaya, mutu, waktu, menggunakan Metode Konvensional dan dengan menggunakan BIM dan tanggapan dari drafter dan engineer menanggapi adanya metode BIM.

Tujuan penelitian ini adalah untuk mengetahui perbandingan proses pembuatan shopdrawing dan metode kerja menggunakan metode konvensional dengan metode BIM sesuai pengendalian biaya, mutu, dan waktu pada perencanaan pekerjaan proyek Jalan Tol Jakarta - Cikampek II Selatan (Paket 3), Mengetahui keunggulan metode BIM dibandingkan dengan metode konvensional, dan menganalisis hasil perbandingan kedua metode dalam pelaksanaan perencanaan proyek konstruksi yang diukur dalam parameter efisiensi biaya, mutu, waktu menggunakan metode konvensional dan metode BIM. Manfaat dari penelitian ini adalah untuk mengetahui perbandingan menggunakan metode BIM dengan metode konvensional.

\section{METODOLOGI PENELITIAN}

Lokasi penelitian ini adalah Proyek pembangunan Jalan Tol Jakarta Cikampek II Selatan Paket 3 (STA.
$34+150$ - STA. $62+000)$ yang menjadi dasar acuan dalam penulisan penelitian ini. Proyek ini merupakan jalan tol baru yang menghubungkan ruas jalan tol JORR dengan ruas tol Purbaleunyi. Penelitian ini berlokasi di Kabupaten Karawang dan Purwakarta, Jawa Barat.

Populasi adalah wilayah generalisasi yang terdiri atas, obyek/subjek yang mempunyai kuantitas dan karakteristik tertentu yang ditetapkan oleh peneliti untuk dipelajari dan ditarik kesimpulannya [11]. Jumlah populasi pada penelitian ini berjumlah 600 orang. Kriteria dalam populasi penelitian ini yaitu dari Dept. Engineering PT. Waskita Karya (Tbk). Dari batasan masalah serta kualifikasi dan klasifikasi yang ditetapkan oleh peneliti, maka didapatkan populasi sejumlah 14 orang yang selaras dengan pertanyaan yang dijadikan kuesioner. Selanjutnya dilakukan perhitungan untuk penentuan jumlah sampel yang dilakukan menggunakan metode Slovin. Dari populasi yang didapat, diperoleh jumlah sampel sebesar:

$$
\begin{gathered}
n=\frac{14}{1+14 \times 0,1^{2}} \\
n=12,28 \approx 12 \text { Sampel }
\end{gathered}
$$

Metode dan tahapan penelitian dapat dilihat pada gambar 1 . 


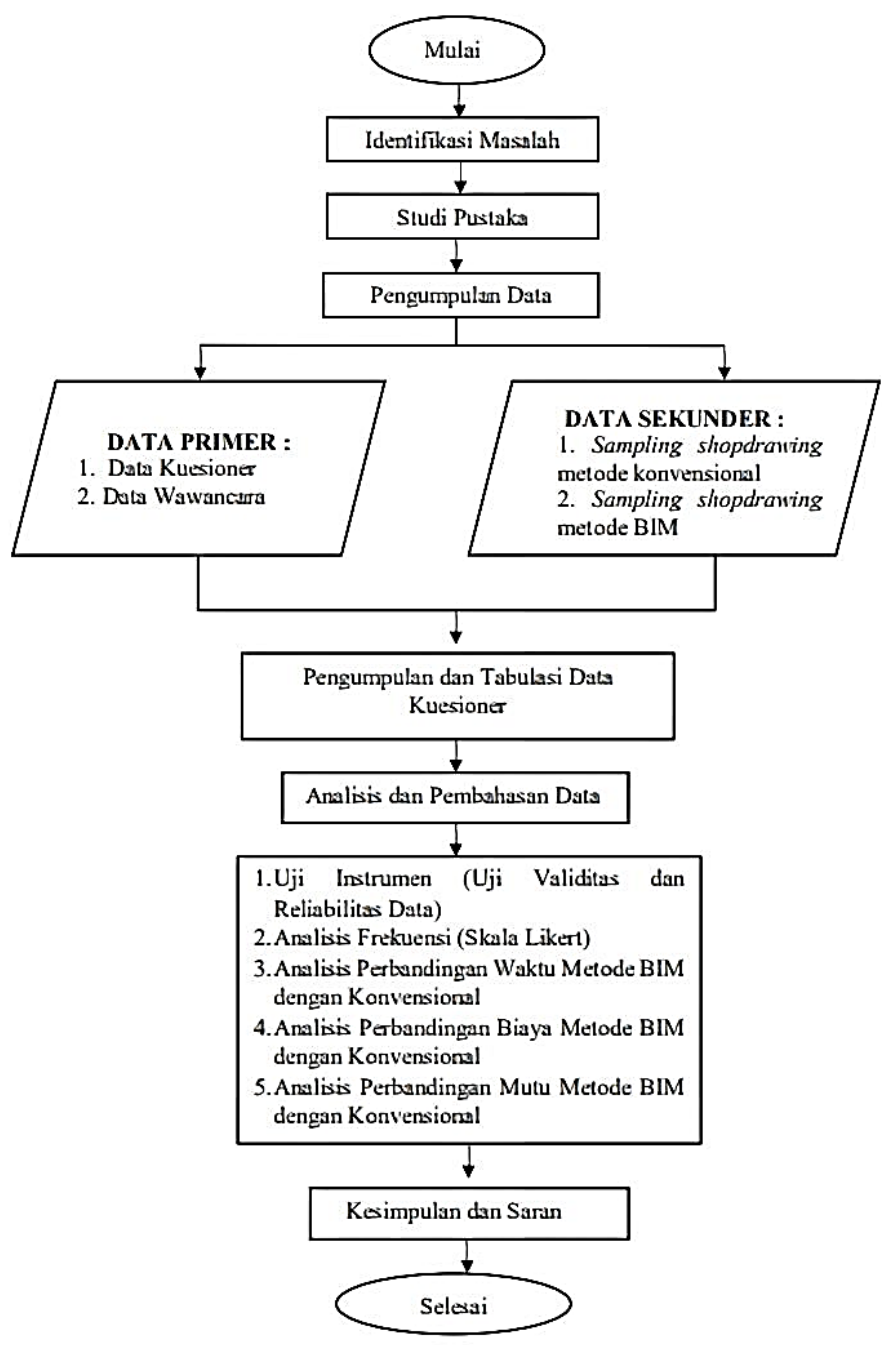

Gambar 1. Bagan Alir Penelitian

\section{HASIL DAN PEMBAHASAN}

\section{Uji Validitas}

Uji Validitas dilakukan menggunakan SPSS dengan menggunakan metode corrected-item-correlation dan membandingkan nilai $r$ hitung yang didapatkan dengan nilai $r$ tabel. Setelah dilakukan analisis 25 pertanyaan maka didapatkan hasil 5 variabel yang tidak valid dengan nilai corrected item total correlation kurang dari 0.576 , sehingga dapat disimpulkan bahwa variabel tersebut harus dikeluarkan dari kuesioner. Setelah variabel pernyataan yang tidak valid dihapus, kuesioner ini selanjutnya divalidasi ulang untuk memastikan bahwa semua pernyataan yang tersisa telah banar-benar valid. Dengan cara yang sama hasil dari output SPSS sudah menunjukkan bahwa semua variabel 20 pernyataan telah valid. seperti berikut

\section{Uji Reliabilitas}

Uji reliabilitas menggunakan SPSS dengan metode Cronbach's Alpha dengan membandingkan nilai $r$ hitung yang didapatkan dengan nilai $r$ tabel. Dari hasil yang telah diuji didapatkan nilai cronbach's alpha lebih besar dari nilai $r$ tabel, sehingga kuesioner ini dikatakan reliabel dalam jurnal (Ghozali, 2012).

\section{Analisis Frekuensi (Skala Likert)}

Berdasarkan data kuesioner pengendalian mutu, data diolah menggunakan metode skala likert pada setiap pertanyaan. Yang pertama kali dilakukan yaitu menghitung Nilai Maksimum, Nilai Minimum, Interval (rentang jarak), dan interpretasi persen atau TCR (Tingkat Pencapaian Responden). Berikut ini adalah rumusrumus yang digunakan

Nilai Maksimum $=$ Skor Tertinggi $\mathrm{x}$ Jumlah Responden

Nilai Minumum $=$ Skor Terendah $\mathrm{x}$ Jumlah Responden

$$
\begin{array}{ll}
\text { Interval (I) } & =\frac{100}{\text { Jumlah Skor (Likert) }} \\
\text { TCR } & =\frac{\text { Rata }- \text { rata skor } x 100}{\text { Skor Maksimum }}
\end{array}
$$

Rata - rata Skor $=$ Total Skor: Jumlah Responden

\section{Analisis Perbandingan Waktu Metode BIM dengan Metode Konvensional}

Tahapan penggunaan metode konvensional dapat dikatakan lebih lama daripada BIM dari hasil yang telah dihitung. Dari analisis kuesioner dan 
wawancara dari responden, penggunaan aplikasi BIM pada perencanaan proyek mampu meningkatkan efisiensi waktu daripada menggunakan metode konvensional. Waktu yang dibutuhkan untuk perencanaan uraian pekerjaan tersebut dengan menggunakan BIM $43.82 \%$ lebih cepat atau hampir dua kali lipat dibandingkan dengan menggunakan metode konvensional. Angka tersebut diperoleh dari perbandingan antara selisih antara metode BIM dengan konvensional dibandingkan dengan metode konvensional.

\section{Perbandingan Biaya Metode BIM dengan Metode Konvensional}

Perbandingan biaya antara metode konvensional dan BIM berdasarkan hasil dari wawancara dengan narasumber yaitu Pak Taufiq sebagai BIM Infrastructure Expert dan juga selaku tim pengadaan PT. Waskita Karya (Persero) Tbk. tentang biaya yang harus dikeluarkan untuk output dari pekerjaan proyek konstruksi khususnya dalam pembuatan metode kerja dan shopdrawing dimulai dari biaya software yang sangat mahalnya harga lisensi, kemudian biaya hardware dimana untuk metode BIM untuk dapat bekerja secara maksimal diperlukan RAM yang besar, graphics card, dan lainnya yang pasti membutuhkan spesifikasi hardware yang besar. Hal ini merupakan biaya investasi awal dari pembuatan shopdrawing pada perencanaan pekerjaan konstruksi. Setelahnya, dapat meningkatkan produktifitas masing-masing drafter dan engineer. Yang awalnya membutuhkan waktu 1 bulan untuk waktu perencanaan dan planning pekerjaan, dengan adanya BIM dapat dilakukan hanya dalam waktu 1 minggu saja.

Hasil akhir dari analisis kuesioner ini menggunakan analisis likert dengan Ms. Excel dan bantuan software SPSS untuk memperkuat hasil perhitungan. Hasil akhirnya dapat disimpulkan menjadi 4 bagian sesuai dengan masing-masing pekerjaan sebagai berikut:

\section{Pembuatan Metode Kerja}

Pelaksanaan Pekerjaan

Pada pekerjaan pembuatan metode kerja dapat disimpulkan bahwa metode BIM lebih baik hasil mutunya karena lebih relevan dengan pekerjaan dilapangan. Berbeda dengan metode konvensional yang outputnya hanya menggunakan aplikasi paint atau powerpoint. Hal ini dapat dilihat pada gambar 2:
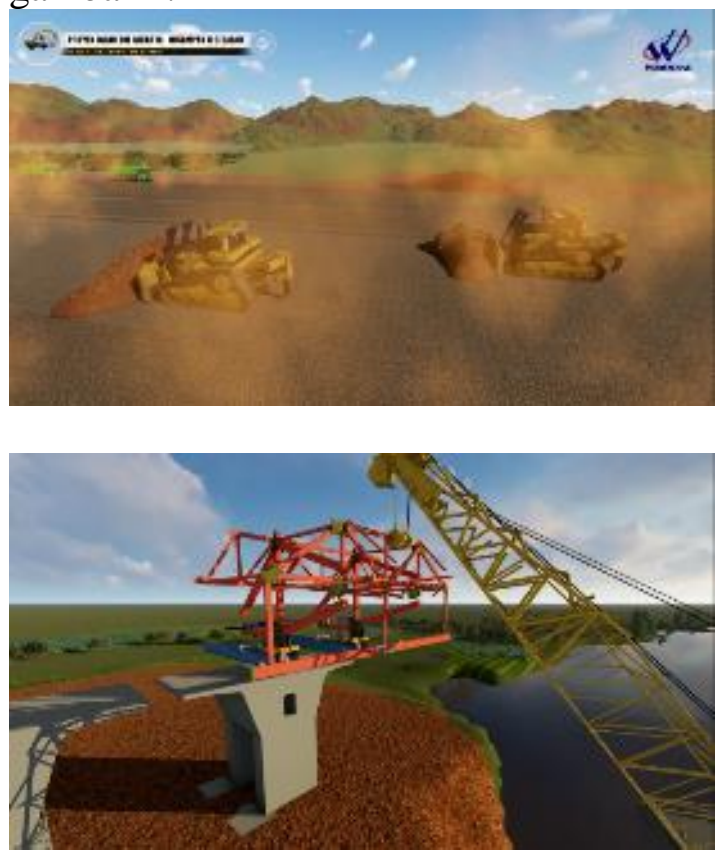

Gambar 2. Pembuatan Metode Kerja menggunakan metode BIM Sumber: PT. Waskita Karya

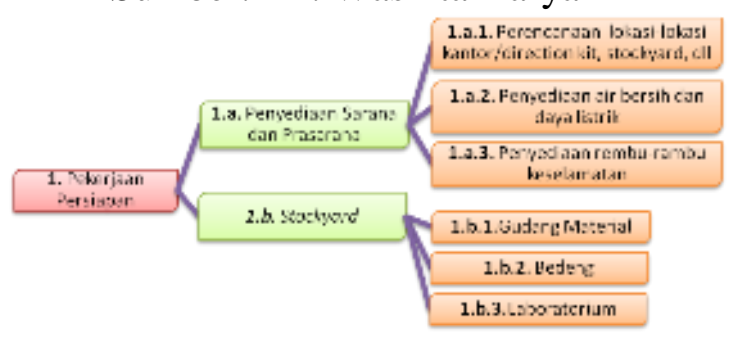

Gambar 3. Pembuatan Metode Kerja menggunakan metode Konvensional

2. Pembuatan Shopdrawing 
Dari hasil analisis perhitungan menggunakan metode likert didapat kesimpulan bahwa responden masih ada yang beranggapan bahwa pembuatan shopdrawing menggunakan BIM lebih baik dan lebih mudah, tetapi juga ada yang masih menggunakan metode konvensional karena BIM masih termasuk "barang baru" sehingga masih beberapa orang belum terbiasa dengan menggunakan BIM jadi masih ada yang memilih metode konvensional juga. Adanya metode BIM terdapat beberapa kelebihan lainnya saat proses pembuatan shopdrawing seperti memudahkan proses stake out di lapangan karena memudahkan tim survei pada pekerjaannya, tingkat efisisiensi dan efektifitas lebih tinggi saat pembuatan gambar untuk pekerjaan struktur jembatan dan pekerjaan lain, menghasilkan model yang akurat. Tetapi terdapat beberapa kekurangan juga pada metode BIM yang serig dikeluhkan oleh responden yaitu sering mengalami lambat/bug.

Untuk lebih jelas hasil perbandingan pembuatan shopdrawing menggunakan BIM dengan konvensional dapat dilihat pada gambar 4:

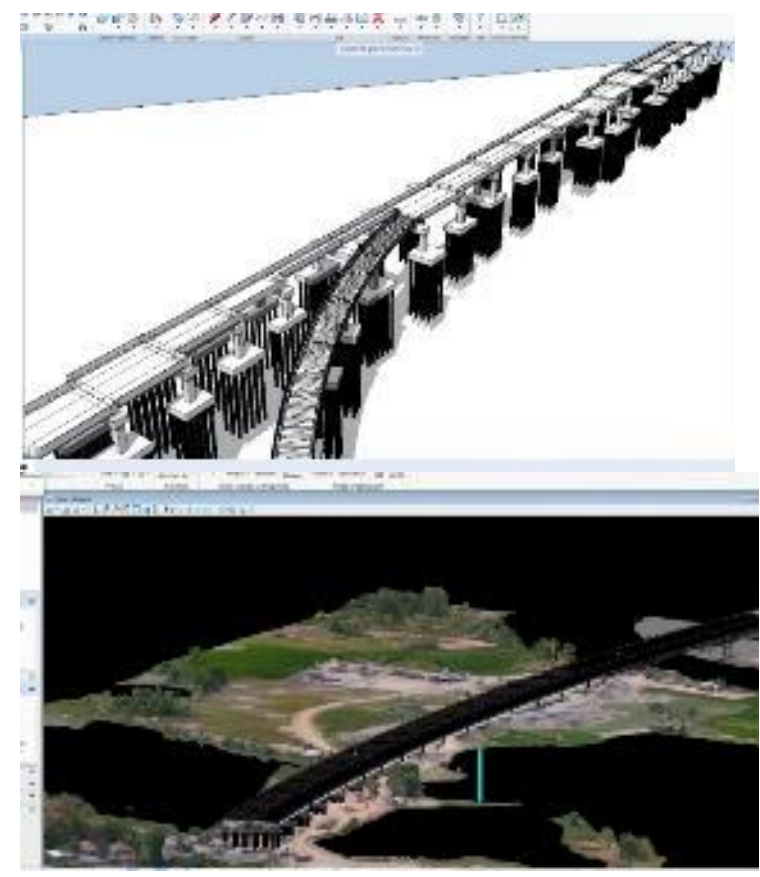

Gambar 4. Pembuatan shopdrawing menggunakan BIM (Allplan Engineering) Sumber: PT. Waskita Karya
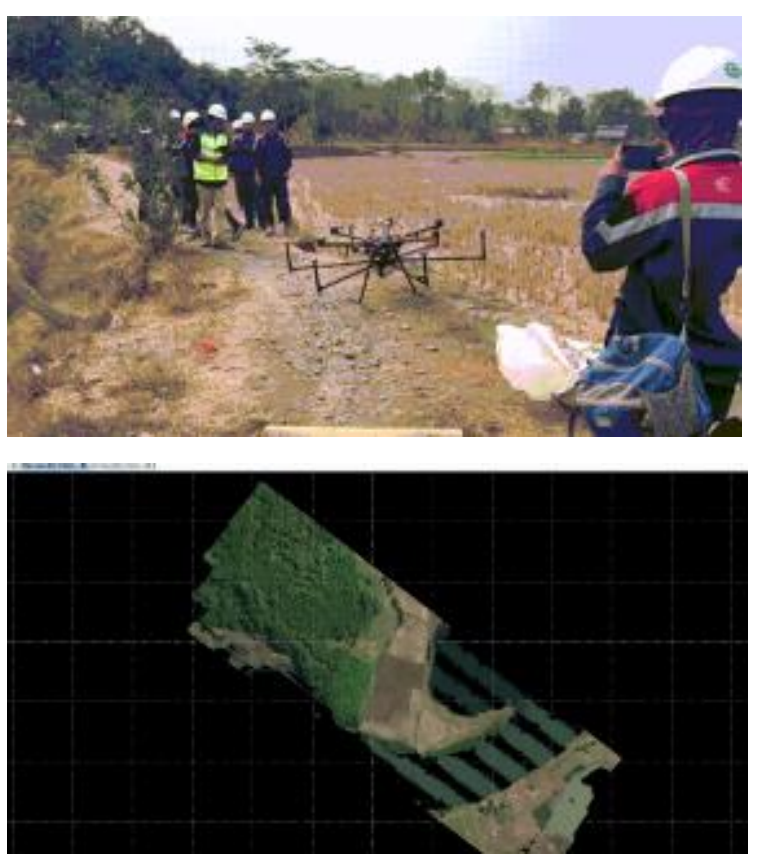

Gambar 5. Proses Survei menggunakan teknologi Lidar Sumber: PT. Waskita Karya

3. Pembuatan As-built-drawing

Dari hasil analisis perhitungan menggunakan metode likert didapat kesimpulan bahwa responden semua setuju bahwa hasil mutu dari as-builtdrawing mengunakan BIM lebih baik dan lebih relevan dengan lapangan. Perbedaan hasil output as-built-drawing menggunakan BIM dan konvensional dapat dilihat pada gambar 6 dan 7: 


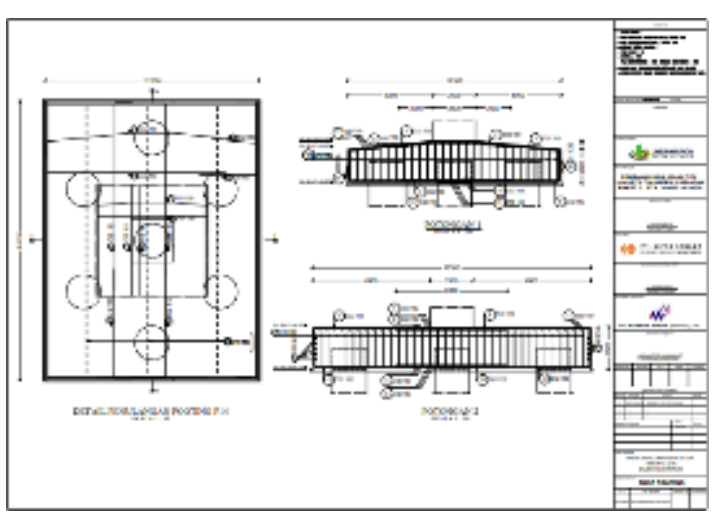

Gambar 6. Hasil gambar as-builtdrawing menggunakan BIM Sumber: PT. Waskita Karya

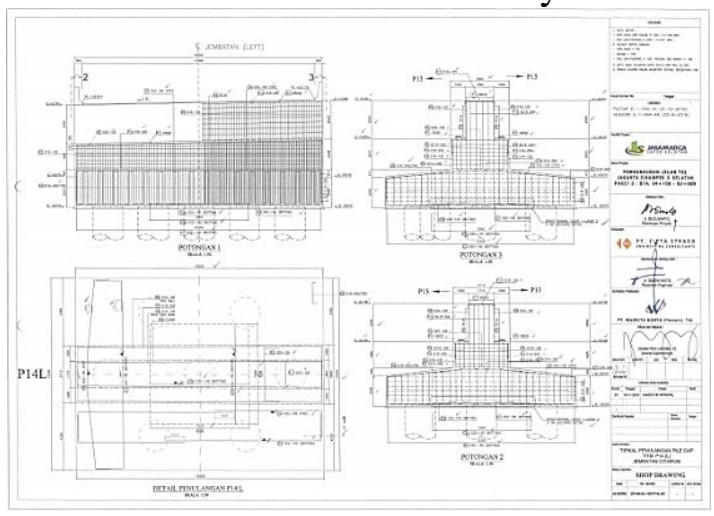

Gambar 7. Hasil gambar as-builtdrawing menggunakan metode Konvensional

\section{Tingkat Keamanan Data}

Dari hasil analisis yang telah dilakukan bahwa untuk tingkat keamanan data pada saat proses pertukaran data menggunakan $\mathrm{CDE}$ sejauh ini cukup aman dan tidak terdapat masalah.

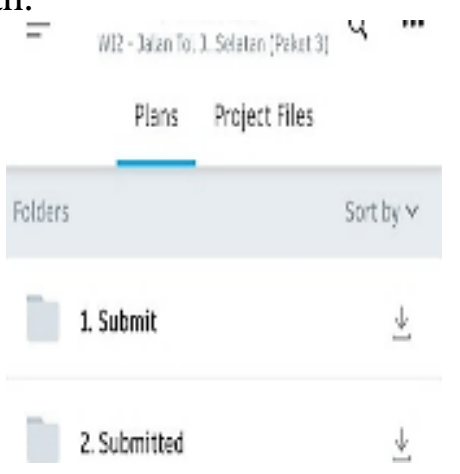

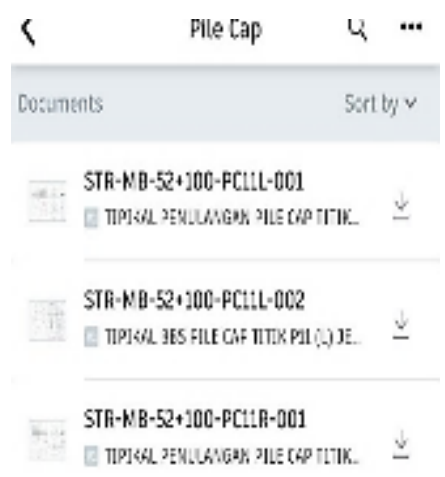

Gambar 8. Distribusi Gambar menggunakan menggunakan $\mathrm{CDE}$ aplikasi BIM360

Sumber: PT. Waskita Karya

\section{KESIMPULAN}

Dari analisa kuesioner dan wawancara dari responden, penggunaan aplikasi BIM pada perencaan proyek mampu meningkatkan efisiensi waktu. Waktu yang dibutuhkan untuk perencanaan uraian pekerjaan tersebut dengan menggunakan BIM 43.82\% lebih cepat atau hampir dua kali lipat dibandingkan dengan menggunakan metode konvensional.

Dari perbandingan biaya antara metode konvensional dengan BIM berdasarkan hasil dari wawancara dengan narasumber didapatkan metode BIM harganya lebih mahal dibandingkan dengan metode konvensional. Biaya yang harus dikeluarkan untuk output dari pekerjaan proyek konstruksi khususnya dalam pembuatan metode kerja dan shopdrawing dimulai dari biaya software yang sangat mahalnya harga lisensi, kemudian biaya hardware dimana untuk metode BIM untuk dapat bekerja secara maksimal diperlukan RAM yang besar, graphics card, dan lainnya yang pasti membutuhkan spesifikasi hardware yang besar.

Hasil dari kuesioner perbandingan mutu dari menggunakan metode konvensional dan BIM yaitu terletak pada hasil mutu atau output dari pembuatan metode kerja, 
shopdrawing, as-built-drawing, dan juga tingkat keamanan data yang menunjukkan bahwa BIM lebih unggul dari metode konvensional.

\section{UCAPAN TERIMA KASIH}

Terimakasih peneliti sampaikan kepada seluruh staff Dept. Engineering PT. Waskita Karya (Persero) Tbk yang telah banyak membantu dalam penyelesain penelitin ini.

\section{DAFTAR PUSTAKA}

[1] R. Amalia, Studi Literatur tentang Program Bantu Autodesk Revit Structure. Teknik Sipil ITS. 2010.

[2] S. Azhar, A. Nadeem, J. Y. N. Mok, dan B. H. Y. Leung, Building Information Modeling (BIM): A New Paradigm for Visual Interactive Modeling and Simulation for Construction Projects. First International Conference on Construction in Developing Countries (ICCIDC-I), Karachi, Pakistan. 4-5 Agustus 2008.

[3] A. S. E. Purba, Analisis Perbandingan Biaya dan Waktu Metode Pelaksanaan Beton In Situ Dengan Precast. Kampus USU, Medan. 2016.

[4] S. Azhar, A. Nadeem, J. Y. N. Mok, dan B. H. Y. Leung, Building Information Modeling (BIM): A New Paradigm for Visual Interactive Modeling and Simulation for Construction Projects. First International Conference on Construction in Developing Countries (ICCIDC-I), Karachi, Pakistan. 4-5 Agustus 2008.

[5] S. Deke, An Introduction to Building Information Modelling (BIM). Journal of Building Infromation Modelling, 4-12. 2007.

[6] Rayendra dan B. W. Soemardi, Studi Aplikasi Teknologi Building Information Modelling untuk PraKonstruksi. ITB, Bandung. 2014.
[7] Toma. M, Analisis Produktivitas Tenaga Kerja Pada Pekerjaan Pasangan Bata (Studi Kasus Proyek Pembangunan Rumah Sakit Dr, Moewardi, Surakarta). Universitas Sebelas Maret, Surakarta. 2010

[8] D. Suriyadi, Pengendalian Biaya Proyek. Universitas Mercu Buana, Bekasi. 2016

[9] Rivelino dan A. Soekiman, Kajian Pengendalian Mutu Konstruksi Pada Pengawasan Pelaksanaan Pembangunan Jaringan Irigasi. Universitas Katolik Parahyangan, Bandung. 2016.

[10] A. Husen, Pengendalian Biaya Manajemen Proyek, Penerbit ANDI, Yogyakarta. 2010

[11] Sugiyono, Metode Penelitian Kuantitatif, Kualitatif dan R\&D. Alfabeta, Bandung. 2007 
Rizal M., Nunung M., Hari P., Perbandingan Metode Konvensional dan BIM...

\section{Lampiran}

Tabel 1. Total Perbandingan waktu menggunakan metode konvensional dan BIM

\begin{tabular}{|c|c|c|c|}
\hline No & Uraian Pekerjaan & $\begin{array}{c}\text { Metode } \\
\text { Konvensional }\end{array}$ & Metode BIM \\
\hline 1 & $\begin{array}{l}\text { Pembuatan } \\
\text { Pekerjaan }\end{array}$ & 34 Hari & 26 Hari \\
\hline 2 & Pembuatan Shopdrawing & 54 Hari & 34 Hari \\
\hline 3 & Pembuatan As-built-drawing & 40 Hari & 29 Hari \\
\hline
\end{tabular}

Sumber: olahan pribadi

Tabel 2. Rata-rata perbandingan waktu perhari

\begin{tabular}{clccc}
\hline No & \multicolumn{2}{c}{ Uraian Pekerjaan } & Metode Konvensional & Metode BIM \\
\hline 1 & $\begin{array}{l}\text { Pembuatan Metode } \\
\text { Pelaksanaan Pekerjaan }\end{array}$ & Kerja & $2.83 \approx 3$ Hari & $2.17 \approx 2$ Hari \\
\hline 2 & Pembuatan Shopdrawing & $4.5 \approx 5$ Hari & $2.83 \approx 3$ Hari \\
\hline 3 & Pembuatan As-built-drawing & $3.33 \approx 3$ Hari & $2.42 \approx 2$ Hari \\
\hline
\end{tabular}

Sumber: olahan pribadi

Tabel 3. Perbandingan biaya metode konvensional dan metode BIM

\begin{tabular}{cccc}
\hline No & Uraian & $\begin{array}{c}\text { Metode } \\
\text { Konvensional }\end{array}$ & Metode BIM \\
\hline 1 & Biaya & Rp. $60,338,000 .-$ & Rp. 441,000,000.- \\
\hline \multicolumn{3}{c}{ Sumber: olahan pribadi }
\end{tabular}

Kıncıan pıaya menggunakan apıkası konvensıonaı

Biaya Software

\begin{tabular}{cllr}
\hline No & \multicolumn{1}{c}{ Nama Software } & \multicolumn{1}{c}{ Harga } \\
\hline 1 & Autodesk AutoCAD & $\mathrm{Rp}$ & $20,000,000.00$ \\
2 & Licensi OS Windows & $\mathrm{Rp}$ & $1,500,000.00$ \\
3 & Plug-in CAD Tools & $\mathrm{Rp}$ & $2,000,000.00$ \\
\hline \multicolumn{2}{c}{ Total } & $\mathrm{Rp}$ & $23,500,000.00$ \\
\hline
\end{tabular}

Biaya Pengadaan Alat (Hardware)

\begin{tabular}{cllllllr}
\hline No & & Jenis Hardware & \multicolumn{2}{c}{ Harga per Satuan Unit } & Jumlah & \multicolumn{2}{c}{ Total Harga } \\
\hline 1 & PC Standard & & $\mathrm{Rp}$ & $10,000,000.00$ & 1 & $\mathrm{Rp}$ & $10,000,000.00$ \\
2 & Laptop Standard & & $\mathrm{Rp}$ & $15,000,000.00$ & 1 & $\mathrm{Rp}$ & $15,000,000.00$ \\
\hline & & & & & 2 & $\mathrm{Rp}$ & $25,000,000.00$ \\
\hline
\end{tabular}

Biaya Pelatihan Engineer/Drafter

\begin{tabular}{cccr} 
No & Jenis Pelatihan & \multicolumn{2}{c}{ Harga Pelatihan } \\
1 & Open Road Designer Training & Rp & $11,838,000.00$
\end{tabular}


Rizal M., Nunung M., Hari P., Perbandingan Metode Konvensional dan BIM...

Rincian biaya menggunakan aplikasi BIM

Biaya Software

\begin{tabular}{|c|c|c|c|c|c|c|}
\hline No & Nama Software & & Harga & & & \\
\hline 1 & Bentley OpenRoad Designer & $\mathrm{Rp}$ & $26,000,000.00$ & & & \\
\hline 2 & Autodesk Civil 3D (AEC Collection) & $\mathrm{Rp}$ & $115,000,000.00$ & & & \\
\hline 3 & All Plan Engineering & $\mathrm{Rp}$ & $120,000,000.00$ & & & \\
\hline & Total & $\mathrm{Rp}$ & $261,000,000.00$ & & & \\
\hline Biaya $\mathrm{P}$ & gadaan Alat (Hardware) & & & & & \\
\hline No & Jenis Hardware & $\mathrm{Ha}$ & ger Satuan Unit & Jumlah & & tal Harga \\
\hline 1 & PC Standard & $\mathrm{Rp}$ & $10,000,000.00$ & 1 & $\mathrm{Rp}$ & $10,000,000.00$ \\
\hline 2 & Laptop Standard & $\mathrm{Rp}$ & $15,000,000.00$ & 1 & $\mathrm{Rp}$ & $15,000,000.00$ \\
\hline & Total & & & 2 & $\mathrm{Rp}$ & $25,000,000.00$ \\
\hline
\end{tabular}

\begin{tabular}{cllc}
\multicolumn{2}{l}{ Biaya Pelatihan Engineer/Drafter } & \multicolumn{2}{c}{ Harga Pelatihan } \\
\hline No & \multicolumn{1}{c}{ Jenis Pelatihan } & \multicolumn{2}{c}{. } \\
\hline \multirow{2}{*}{1} & $\begin{array}{l}\text { Training Software Bentley OpenRoad } \\
\text { Designer }\end{array}$ & $\mathrm{Rp}$ & $60,000,000.00$ \\
2 & $\begin{array}{l}\text { Training Software All Plan Engineering } \\
3\end{array}$ & $\mathrm{Rp}$ & $95,000,000.00$ \\
\hline & Training Software Autodesk Civil 3D & $\mathrm{Rp}$ & \\
\hline & Total & $\mathrm{Rp}$ & $155,000,000.00$
\end{tabular}

Gambar 9. Hasil Wawancara Analisis Perbandingan Harga Metode Konvensional dengan BIM

Tabel 4. Analisis Perbandingan Mutu Metode Konvensional dan metode BIM

\begin{tabular}{|c|c|c|}
\hline No & TCR & Kategori \\
\hline 1 & $66.67 \%$ & $\begin{array}{l}\text { Lebih dari setengah } \\
\text { responden Setuju }\end{array}$ \\
\hline 2 & $83.33 \%$ & $\begin{array}{lr}\text { Sebagian } & \text { besar } \\
\text { responden } & \text { Sangat } \\
\text { Setuju } & \\
\end{array}$ \\
\hline 3 & $68.75 \%$ & $\begin{array}{l}\text { Lebih dari setengah } \\
\text { responden Setuju }\end{array}$ \\
\hline 4 & $79.17 \%$ & $\begin{array}{lr}\text { Sebagian } & \text { besar } \\
\text { responden } & \text { Sangat } \\
\text { Setuju } & \\
\end{array}$ \\
\hline 5 & $68.75 \%$ & $\begin{array}{l}\text { Lebih dari setengah } \\
\text { responden Setuju }\end{array}$ \\
\hline 6 & $83.33 \%$ & $\begin{array}{lr}\text { Sebagian } & \text { besar } \\
\text { responden } & \text { Sangat } \\
\text { Setuju } & \\
\end{array}$ \\
\hline 7 & $70.83 \%$ & $\begin{array}{l}\text { Lebih dari setengah } \\
\text { responden Setuju }\end{array}$ \\
\hline 8 & $64.58 \%$ & $\begin{array}{l}\text { Lebih dari setengah } \\
\text { responden Setuju }\end{array}$ \\
\hline 9 & $83.33 \%$ & $\begin{array}{lr}\text { Sebagian } & \text { besar } \\
\text { responden } & \text { Sangat } \\
\text { Setuju } & \\
\end{array}$ \\
\hline 10 & $83.33 \%$ & $\begin{array}{l}\text { Sebagian } \\
\text { responden } \\
\text { Setuju } \\
\end{array}$ \\
\hline 11 & $79.17 \%$ & $\begin{array}{lr}\text { Sebagian } & \text { besar } \\
\text { responden } & \text { Sangat } \\
\text { Setuju } & \\
\end{array}$ \\
\hline
\end{tabular}

\begin{tabular}{|c|c|c|}
\hline & $2.92 \%$ & $\begin{array}{l}\text { ari setengah } \\
\text { en Setuju }\end{array}$ \\
\hline 13 & $79.17 \%$ & $\begin{array}{lr}\text { Sebagian } & \text { besar } \\
\text { responden } & \text { Sangat } \\
\text { Setuju } & \end{array}$ \\
\hline 14 & $64.58 \%$ & $\begin{array}{l}\text { Lebih dari setengah } \\
\text { responden Setuju }\end{array}$ \\
\hline 15 & $\%$ & $\begin{array}{lr}\text { Sebagian } & \text { besar } \\
\text { responden } & \text { Sangat } \\
\text { Setuju } & \end{array}$ \\
\hline 6 & $2 \%$ & $\begin{array}{l}\text { Lebih dari setengah } \\
\text { responden Setuju }\end{array}$ \\
\hline 17 & $79.17 \%$ & $\begin{array}{lr}\text { Sebagian } & \text { besar } \\
\text { responden } & \text { Sangat } \\
\text { Setuju } & \end{array}$ \\
\hline 18 & $33 \%$ & $\begin{array}{l}\text { Sebagian } \\
\text { responden } \\
\text { Setuju }\end{array}$ \\
\hline 19 & $2.92 \%$ & Lebih dari $\mathrm{s}$ \\
\hline 20 & $7 \%$ & $\begin{array}{lr}\text { Sebagian } & \text { besar } \\
\text { responden } & \text { Sangat } \\
\text { Setuju } & \\
\end{array}$ \\
\hline
\end{tabular}

